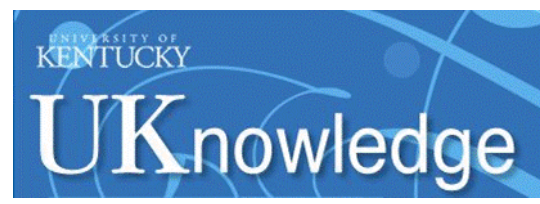

University of Kentucky

UKnowledge

\title{
Comparison of Transcutaneous Electrical Nerve Stimulation and Cryotherapy for Increasing Quadriceps Activation in Patients With Knee Pathologies
}

Conrad M. Gabler

University of Kentucky, gabler.cm@uky.edu

Adam S. Lepley

University of Kentucky, adam.lepley@uky.edu

Timothy L. Uhl

University of Kentucky, tluhl2@uky.edu

Carl G. Mattacola

University of Kentucky, carlmattacola@uky.edu

Follow this and additional works at: https://uknowledge.uky.edu/rehabsci_facpub

Part of the Rehabilitation and Therapy Commons

Right click to open a feedback form in a new tab to let us know how this document benefits you.

\section{Repository Citation}

Gabler, Conrad M.; Lepley, Adam S.; Uhl, Timothy L.; and Mattacola, Carl G., "Comparison of Transcutaneous Electrical Nerve Stimulation and Cryotherapy for Increasing Quadriceps Activation in Patients With Knee Pathologies" (2015). Physical Therapy Faculty Publications. 47.

https://uknowledge.uky.edu/rehabsci_facpub/47

This Article is brought to you for free and open access by the Physical Therapy at UKnowledge. It has been accepted for inclusion in Physical Therapy Faculty Publications by an authorized administrator of UKnowledge. For more information, please contact UKnowledge@lsv.uky.edu. 
Comparison of Transcutaneous Electrical Nerve Stimulation and Cryotherapy for Increasing Quadriceps Activation in Patients With Knee Pathologies

Digital Object Identifier (DOI)

http://dx.doi.org/10.1123/jsr.2014-0292

Notes/Citation Information

To be published in Journal of Sport Rehabilitation.

(C) 2015 Human Kinetics, Inc. as accepted for publication. http://dx.doi.org/10.1123/jsr.2014-0292

This article is available at UKnowledge: https://uknowledge.uky.edu/rehabsci_facpub/47 


\section{Note: This article will be published in a forthcoming issue of the Journal of Sport Rehabilitation. The article appears here in its accepted, peer-reviewed form, as it was provided by the submitting author. It has not been copyedited, proofed, or formatted by the publisher.}

Section: Critically Appraised Topic

Article Title: Comparison of Transcutaneous Electrical Nerve Stimulation and Cryotherapy for Increasing Quadriceps Activation in Patients With Knee Pathologies

Authors: Conrad M. Gabler ${ }^{1}$, Adam S. Lepley ${ }^{2}$, Tim L. Uhl ${ }^{1}$, and Carl G. Mattacola ${ }^{1}$

Affiliations: ${ }^{1}$ Department of Rehabilitation Sciences, Athletic Training Program, University of Kentucky, Lexington, KY. ${ }^{2}$ Department of Kinesiology and Health Promotion, University of Kentucky, Lexington, KY.

Running Head: Improving quad activation: TENS vs. Cryotherapy

Journal: Journal of Sport Rehabilitation

Acceptance Date: December 12, 2014

(C)2015 Human Kinetics, Inc.

DOI: http://dx.doi.org/10.1123/jsr.2014-0292 
"Comparison of Transcutaneous Electrical Nerve Stimulation and Cryotherapy for Increasing Quadriceps Activation in Patients With Knee Pathologies" by Gabler CM, Lepley AS, Uhl TL, Mattacola CG

Journal of Sport Rehabilitation

(C) 2015 Human Kinetics, Inc.

Title: Comparison of transcutaneous electrical nerve stimulation and cryotherapy for increasing quadriceps activation in patients with knee pathologies

Authors:

Conrad M. Gabler, MS, ATC ${ }^{1}$

Adam S. Lepley, PhD, ATC ${ }^{2}$

Tim L. Uhl, PhD, ATC, $\mathrm{PT}^{1}$

Carl G. Mattacola, PhD, ATC, FNATA ${ }^{1}$

Affiliations:

${ }^{1}$ Department of Rehabilitation Sciences, Athletic Training Program, University of Kentucky, Lexington, KY, USA 40536

${ }^{2}$ Department of Kinesiology and Health Promotion, University of Kentucky, Lexington, KY 40536

Corresponding Author:

Conrad Gabler, MS, ATC

Department of Rehabilitation Sciences, Athletic Training

Charles T. Wethington Jr. Building, $2^{\text {nd }}$ Floor

900 South Limestone, Room 214C

Lexington, KY 40536-0200

Office: (859) 218-0578

gabler.cm@uky.edu 


\section{Clinical Scenario}

Proper neuromuscular activation of the quadriceps muscle is essential for maintaining quadriceps strength and lower extremity function. Quadriceps activation failure is a common characteristic observed in patients with knee pathologies, and it is defined as an inability to voluntarily activate the entire alpha motor neuron pool innervating the quadriceps. ${ }^{1}$ One of the more popular techniques used to assess quadriceps activation is the superimposed burst (SIB) technique. ${ }^{2}$ The SIB technique is a force-based technique which uses a supramaximal, percutaneous electrical stimulation to activate all of the motor units in the quadriceps during a maximal, voluntary isometric contraction of the quadriceps. Central activation ratio (CAR) is the formula used to calculate quadriceps activation level (CAR = voluntary force/SIB force) with the SIB technique. People who can voluntary active $95 \%$ or more $(\mathrm{CAR}=0.95-1.0)$ of their motor units are defined as being fully activated. ${ }^{3}$ Therapeutic exercises aimed at improving quadriceps strength in patients with knee pathologies are limited in their effectiveness due to a failure to fully activate the muscle. Within the past decade, several disinhibitory interventions have been introduced to treat quadriceps activation failure in patients with knee pathologies. Transcutaneous electrical nerve stimulation (TENS) and cryotherapy are sensory-targeted modalities traditionally used to treat pain, ${ }^{4,5}$ but they have been shown to be two of the most successful treatments for increasing quadriceps activation levels in patients with quadriceps activation failure ${ }^{6-11}$ Both modalities are hypothesized to positively affect voluntary quadriceps activation by disinhibiting the motor neuron pool of the quadriceps. In essence, these modalities provide excitatory afferent stimuli to the spinal cord, which thereby overrides the inhibitory afferent signaling that arises from the involved joint. ${ }^{6}$ However, it remains unknown as to whether one is more effective than the other for restoring quadriceps activation levels in patients with knee pathologies. By knowing the capabilities of each disinhibitory modality, clinicians can tailor treatments based on the rehabilitation goals of their patients.

Key Words: rehabilitation, neuromuscular system, muscle function 


\section{Focused Clinical Question}

Is TENS or cryotherapy the more effective disinhibitory modality for treating quadriceps activation failure (quantified via CAR) in patients with knee pathologies?

\section{Summary of Search, "Best Evidence” Appraised, and Key Finding}

- The literature was searched for studies of level 3 evidence or higher (based on Oxford Centre of Evidence-Based Medicine 2011, Levels of Evidence) that investigated the effect of TENS and/or cryotherapy interventions for improving quadriceps activation levels in patients with knee pathologies.

- Three moderate to high-quality randomized controlled trial studies ${ }^{9-11}$ were included and critically appraised.

- All three studies ${ }^{9-11}$ supported the use of TENS and/or cryotherapy for improving quadriceps activation levels in patients with diagnosed knee pathologies.

\section{Clinical Bottom Line}

There is sufficient evidence to suggest that both TENS and cryotherapy can be used to improve quadriceps activation levels in patients with knee pathologies who demonstrate quadriceps activation failure. Unlike cryotherapy, TENS can be used in conjunction with most physical activity, and therefore may be the more versatile disinhibitory modality.

Strength of Recommendation: Based upon the American Family Physician's Strength of Recommendation Taxonomy, there is Level B evidence to support the use of either TENS or cryotherapy to improve quadriceps activation levels in patients with knee pathologies. The evidence supports both disinhibitory modalities as being effective treatments for quadriceps activation failure, but proposes TENS to have the most clinical versatility. 


\section{Search Strategy}

\section{Terms Used to Guide Search Strategy}

- Patient/Client group: Knee injury or knee pathology

- Intervention: Transcutaneous electrical nerve stimulation

- Comparison: Cryotherapy or ice

- Outcome: Quadriceps activation or Quadriceps Inhibition (quantified via CAR)

\section{Sources of Evidence Searched}

- PubMed

- CINAHL

- $\quad$ SPORTDiscus

- Medline

- Additional resources obtained via review of reference lists and hand search

\section{Inclusion and Exclusion Criteria}

\section{Inclusion Criteria}

- Studies with a cohort of patients who were diagnosed with a knee pathology/injury [knee osteoarthritis, anterior cruciate ligament (ACL) injury, meniscal injury, patellofemoral pain syndrome] and demonstrated quadriceps activation failure

- Studies using TENS and/or cryotherapy to treat quadriceps activation failure

- Level 3 evidence or higher

- Limited to English language

- Published within the last 10 years (January 1, 2004 to August 1, 2014) 


\section{Exclusion Criteria}

- Studies that did not use a force-based technique to assess quadriceps activation

- Studies involving subjects with post-surgical knee conditions

\section{Results of Search}

Three eligible and relevant studies ${ }^{9-11}$ were categorized as shown in Table 1 (based on Oxford Centre of Evidence-Based Medicine 2011, Levels of Evidence).

\section{Best Evidence}

The studies listed in Table 2 represent the best available evidence and were selected for inclusion in the critically appraised topic (CAT). These studies were selected because they fulfilled the following criteria: grade 3 or higher ${ }^{9-11}$ level of evidence, studied TENS and/or cryotherapy, and reported the effect of these interventions for increasing quadriceps activation levels in patients with diagnosed knee pathologies.

\section{Implications for Practice, Education, and Future Research}

All three studies ${ }^{9-11}$ reviewed in this CAT supported the use of either TENS or cryotherapy as disinhibitory inventions for patients with knee pathologies who demonstrate QAF. The one study ${ }^{10}$ that investigated the effectiveness of TENS alone, reported that a combination of TENS with exercise produced higher CAR in patients with knee osteoarthritis compared to placebo-TENS (with exercise) and exercise alone at various time points within the 4-week intervention. Of the two studies ${ }^{9,11}$ that compared the effectiveness of TENS and cryotherapy, both reported significant improvements in patients' CAR over time, however there were no significant differences between the two interventions. One of the studies ${ }^{11}$ found neither intervention to be more effective than exercise alone for improving CAR in patients with ACL 
“Comparison of Transcutaneous Electrical Nerve Stimulation and Cryotherapy for Increasing Quadriceps Activation in Patients With Knee Pathologies" by Gabler CM, Lepley AS, Uhl TL, Mattacola CG

Journal of Sport Rehabilitation

(C) 2015 Human Kinetics, Inc.

injuries. However, the mean CAR between groups in this study was not equal at baseline, with the exercise-only group having higher baseline CAR than both the TENS and cryotherapy groups. Therefore, the higher baseline CAR observed in the exercise-only group placed them at an advantage, and may have masked the supplementary effect of the cryotherapy and TENS interventions. In other words, the exercise-only group was not very inhibited to prior to beginning their intervention and as a result, may have fallen victim to a ceiling effect. If the exercise-only group was as inhibited as the TENS and cryotherapy groups at baseline, a larger effect from exercise alone may have been observed.

Examining the treatment effect sizes and corresponding 95\% confidence intervals (Table 3) reported in these studies ${ }^{9-11}$ provides better insight into the clinical effectiveness of TENS and cryotherapy for improving quadriceps activation levels in patients with knee pathologies. Effect sizes were calculated using Cohen's D equation (difference in mean CAR from baseline to posttest, divided by the pooled standard deviation of the two means). Compared to the control and placebo groups, the groups assigned to either intervention repeatedly demonstrated stronger and significant (95\% confidence intervals did not cross zero) effect sizes for improving CAR in patients. Furthermore, TENS displayed the strongest effect sizes at each time point, and it was the only intervention to demonstrate significant effect sizes (95\% confidence intervals did not cross zero) for all measurement time points. Figure 1 provides a comparison of effect sizes between TENS and cryotherapy interventions from all three studies. ${ }^{9-11}$ This observation suggests that TENS may be the more clinically effective disinhibitory modality.

When comparing effect sizes between TENS and cryotherapy, an interesting pattern can be observed for the post-treatment measurements. TENS consistently exhibited stronger effect sizes than cryotherapy, and unlike cryotherapy, maintained significant effect sizes at each post- 
“Comparison of Transcutaneous Electrical Nerve Stimulation and Cryotherapy for Increasing Quadriceps Activation in Patients With Knee Pathologies" by Gabler CM, Lepley AS, Uhl TL, Mattacola CG

Journal of Sport Rehabilitation

(C) 2015 Human Kinetics, Inc.

treatment measurement. These findings contradict prior assumptions derived from previous experimental effusion studies, in which spinal reflex excitability remained facilitated longer in the cryotherapy group compared to the TENS group. ${ }^{6}$ The sustained effect of cryotherapy has been attributed to residual cooling of cutaneous nerve endings that is present immediately after treatment, which prolongs the transmission of excitatory afferent information to the spinal cord and continues to disinhibit the joint musculature. ${ }^{6,12}$ Thus, cryotherapy was originally thought to be the superior disinhibitory modality.

A potential explanation for the opposing results of the studies ${ }^{9-11}$ included in this review can be attributed to differences in dosage durations. The studies by Pietrosimone et al. (2009) ${ }^{6}$ and Hart et al. ${ }^{11}$, which compared both disinhibitory modalities, allowed the cryotherapy groups to ice their knee for only 20 minutes, while the TENS group was allowed to wear their TENS unit throughout the measurement period ${ }^{9}$ or exercise session. ${ }^{11}$ Therefore, the reason why these two studies found TENS to have a higher effect sizes than cryotherapy may be largely attributed to the difference in treatment durations. The authors did not provide rationale as to why the cryotherapy groups were only allowed to ice for 20 minutes; however, it may have been instituted as a safety measure. The authors did provide justifiable rationale for why the TENS groups were allowed to wear their TENS units for a longer duration than the cryotherapy groups. In response to the previously reported residual cooling effect observed after cryotherapy removal, ${ }^{6,12}$ the two studies ${ }^{9,11}$ that compared both modalities increased the TENS group's treatment duration to allow for a more fair comparison between the modalities. In the two studies ${ }^{10,11}$ that used TENS in conjunction with exercise, the authors chose to have the TENS groups wear their TENS unit throughout the duration of the exercise sessions in attempts to provide clinical validity. For example, the second study by Pietrosimone et al. $(2011)^{10}$ which 
investigated the effects of TENS alone instructed their subjects to wear their TENS unit at least 8 hours each day and during their exercise sessions. Unlike ice bags, TENS units can be worn during exercise without obstructing movement, and although both modalities may be equally effective at increasing motor neuron pool excitability, the versatility of TENS gives it a clinical advantage over cryotherapy.

The findings from this review suggest TENS to be more effective as a disinhibitory modality for improving quadriceps activation levels in patients with knee pathologies. However, due to differences in dosage parameters and patient population between the three studies, ${ }^{9-11} \mathrm{a}$ superior disinhibitory modality cannot be definitively concluded. The stronger effect sizes and significant post-treatment measurements demonstrated by TENS is most likely attributed to the longer treatment duration ( $\geq 45$ minutes/session) for the TENS groups compared to the 20minute treatment sessions of the cryotherapy groups. It is unknown if longer treatment durations for cryotherapy (> 20 minutes) would mimic the effects of TENS, by exhibiting increased quadriceps activation levels that are sustained for a longer period of time upon removal. Clinicians commonly use shorter durations when applying ice near a superficial peripheral nerve to prevent peripheral neuropathy. A logical solution would be to apply ice to the knee intermittently (i.e., 20 minutes on, $20 \mathrm{~min}$ ) to protect against nerve damage and determine if the disinhibitory effects of cryotherapy can be maximized. Secondly, the patient population in one study ${ }^{11}$ involved patients with ACL injuries, while the other two studies ${ }^{9,10}$ included in this review involved patients with tibiofemoral osteoarthritis. Patients with acute knee pathologies may not have the same response to disinhibitory modalities as do patients with chronic knee pathologies. It has been proposed that the reason ACL-injured patients do not respond to disinhibitory treatments as well as patients with knee osteoarthritis, is because ACL injuries are 
"Comparison of Transcutaneous Electrical Nerve Stimulation and Cryotherapy for Increasing Quadriceps Activation in Patients With Knee Pathologies" by Gabler CM, Lepley AS, Uhl TL, Mattacola CG

Journal of Sport Rehabilitation

(C) 2015 Human Kinetics, Inc.

acute knee injuries that cause considerable pain and inflammation, and often involve multiple joint comorbidities. ${ }^{11}$ Therefore, a greater treatment intensity and duration may be needed for these modalities to successfully override the inhibitory afferent information originating from the knee in patients with acute knee pathologies. Further investigations are needed, especially in patients with acute knee pathologies, to determine the most effective disinhibitory modality for treating quadriceps activation failure.

As is known, quadriceps activation failure can result from swelling and/or pain within a joint. ${ }^{13}$ Therefore, given the inflammatory status of the patient being treated, clinicians may elect to use one of the disinhibitory modalities over the other. Patients with chronic knee pathologies who demonstrate quadriceps activation failure should be instructed to use TENS more than cryotherapy, unless they are attempting to control the onset of swelling and inflammation after exercise or activity. In patients with acute knee pathologies or who have recently undergone knee surgery, cryotherapy may be the more pertinent disinhibitory modality because of its ability to decrease cell metabolism, control edema formation, and reduce pain during the inflammatory phase. ${ }^{5}$ As a patient's pain and swelling diminish, cryotherapy should be administered less and TENS can be introduced more regularly to restore quadriceps activation, control pain, and facilitate exercise. ${ }^{4}$ Cryotherapy can be applied during simple, non-weight-bearing exercises such as seated straight leg raises, but unlike TENS, it impedes movements during more dynamic, weight-bearing exercises. Therefore, TENS should be administered as soon as disinhibited patients no longer have acute knee swelling and they are cleared to perform weight-bearing exercises. 
"Comparison of Transcutaneous Electrical Nerve Stimulation and Cryotherapy for Increasing Quadriceps Activation in Patients With Knee Pathologies" by Gabler CM, Lepley AS, Uhl TL, Mattacola CG

Journal of Sport Rehabilitation

(C) 2015 Human Kinetics, Inc.

\section{Clinical Recommendation}

We conclude that both TENS and cryotherapy are effective modalities for improving quadriceps activation in patients with knee pathologies. However, the versatility of TENS does offer a clinical advantage over cryotherapy by allowing patients to use it during both clinical and daily activities. The recommended treatment guidelines (location, parameters, duration) for clinicians to use to facilitate quadriceps activation can be seen in Table 4. Future investigations should assess long-term ( $>4$ weeks) effects of these interventions, as well as additional disinhibitory modalities that can be used to restore quadriceps activation levels in patients with various knee pathologies.

In addition, it has been hypothesized that TENS and cryotherapy improve voluntary activation by targeting spinal reflexive circuits. ${ }^{14}$ However, if a patient's quadriceps activation failure is not originating from spinal reflexive circuits, but instead corticospinal circuits, these interventions may not be effective. Therefore, disinhibitory interventions need to be selected based on the status of the patient and origin of quadriceps activation failure. A newly published systematic review by Harkey et al. ${ }^{15}$ assessed all of the disinhibitory interventions that have been reported in the literature for improving quadriceps activation. More research efforts such as these are needed to determine the best methods for treating both the spinal and supraspinal origins of quadriceps activation failure. 
“Comparison of Transcutaneous Electrical Nerve Stimulation and Cryotherapy for Increasing Quadriceps Activation in Patients With Knee Pathologies" by Gabler CM, Lepley AS, Uhl TL, Mattacola CG

Journal of Sport Rehabilitation

(C) 2015 Human Kinetics, Inc.

\section{References}

1. Morrissey MC. Reflex inhibition of thigh muscles in knee injury. Causes and treatment. Sports Med. Apr 1989;7(4):263-276.

2. Snyder-Mackler L, De Luca PF, Williams PR, Eastlack ME, Bartolozzi AR, 3rd. Reflex inhibition of the quadriceps femoris muscle after injury or reconstruction of the anterior cruciate ligament. J Bone Joint Surg Am. Apr 1994;76(4):555-560.

3. Park J, Hopkins JT. Quadriceps activation normative values and the affect of subcutaneous tissue thickness. J Electromyogr Kinesiol. Feb 2011;21(1):136-140.

4. Levin MF, Hui-Chan CW. Conventional and acupuncture-like transcutaneous electrical nerve stimulation excite similar afferent fibers. Arch Phys Med Rehabil. Jan 1993;74(1):54-60.

5. Merrick MA, Rankin JM, Andres FA, Hinman CL. A preliminary examination of cryotherapy and secondary injury in skeletal muscle. Med Sci Sports Exerc. Nov 1999;31(11):1516-1521.

6. Hopkins J, Ingersoll CD, Edwards J, Klootwyk TE. Cryotherapy and Transcutaneous Electric Neuromuscular Stimulation Decrease Arthrogenic Muscle Inhibition of the Vastus Medialis After Knee Joint Effusion. J Athl Train. Mar 2002;37(1):25-31.

7. Stokes M, Shakespeare D, Sherman K, Young A. Transcutaneous nerve stimulation and postmeniscectomy quadriceps inhibition. Int J Rehabil Res. 1985;8:248.

8. Rice D, McNair PJ, Dalbeth N. Effects of cryotherapy on arthrogenic muscle inhibition using an experimental model of knee swelling. Arthritis Rheum. Jan 15 2009;61(1):78-83.

9. Pietrosimone BG, Hart JM, Saliba SA, Hertel J, Ingersoll CD. Immediate effects of transcutaneous electrical nerve stimulation and focal knee joint cooling on quadriceps activation. Med Sci Sports Exerc. Jun 2009;41(6):1175-1181.

10. Pietrosimone BG, Saliba SA, Hart JM, Hertel J, Kerrigan DC, Ingersoll CD. Effects of transcutaneous electrical nerve stimulation and therapeutic exercise on quadriceps activation in people with tibiofemoral osteoarthritis. J Orthop Sports Phys Ther. Jan 2011;41(1):4-12.

11. Hart JM, Kuenze CM, Pietrosimone BG, Ingersoll CD. Quadriceps function in anterior cruciate ligament-deficient knees exercising with transcutaneous electrical nerve stimulation and cryotherapy: a randomized controlled study. Clin Rehabil. Nov 2012;26(11):974-981.

12. Krause BA, Hopkins JT, Ingersoll C, Cordova M, Edwards J. The relationship of ankle temperature during cooling and rewarming to the human soleus $\mathrm{H}$ reflex. 1056-6716. 2000;9(3):253-262.

13. Palmieri-Smith RM, Villwock M, Downie B, Hecht G, Zernicke R. Pain and Effusion and Quadriceps Activation and Strength. Journal of athletic training. 2013;48(2):186-191.

14. Hopkins JT, Ingersoll CD, Krause BA, Edwards JE, Cordova ML. Effect of knee joint effusion on quadriceps and soleus motoneuron pool excitability. Med Sci Sports Exerc. Jan 2001;33(1):123126. 
“Comparison of Transcutaneous Electrical Nerve Stimulation and Cryotherapy for Increasing Quadriceps Activation in Patients With Knee Pathologies" by Gabler CM, Lepley AS, Uhl TL, Mattacola CG

Journal of Sport Rehabilitation

(C) 2015 Human Kinetics, Inc.

15. Harkey MS, Gribble PA, Pietrosimone BG. Disinhibitory Interventions and Voluntary Quadriceps Activation: A Systematic Review. J Athl Train. Feb 32014. 


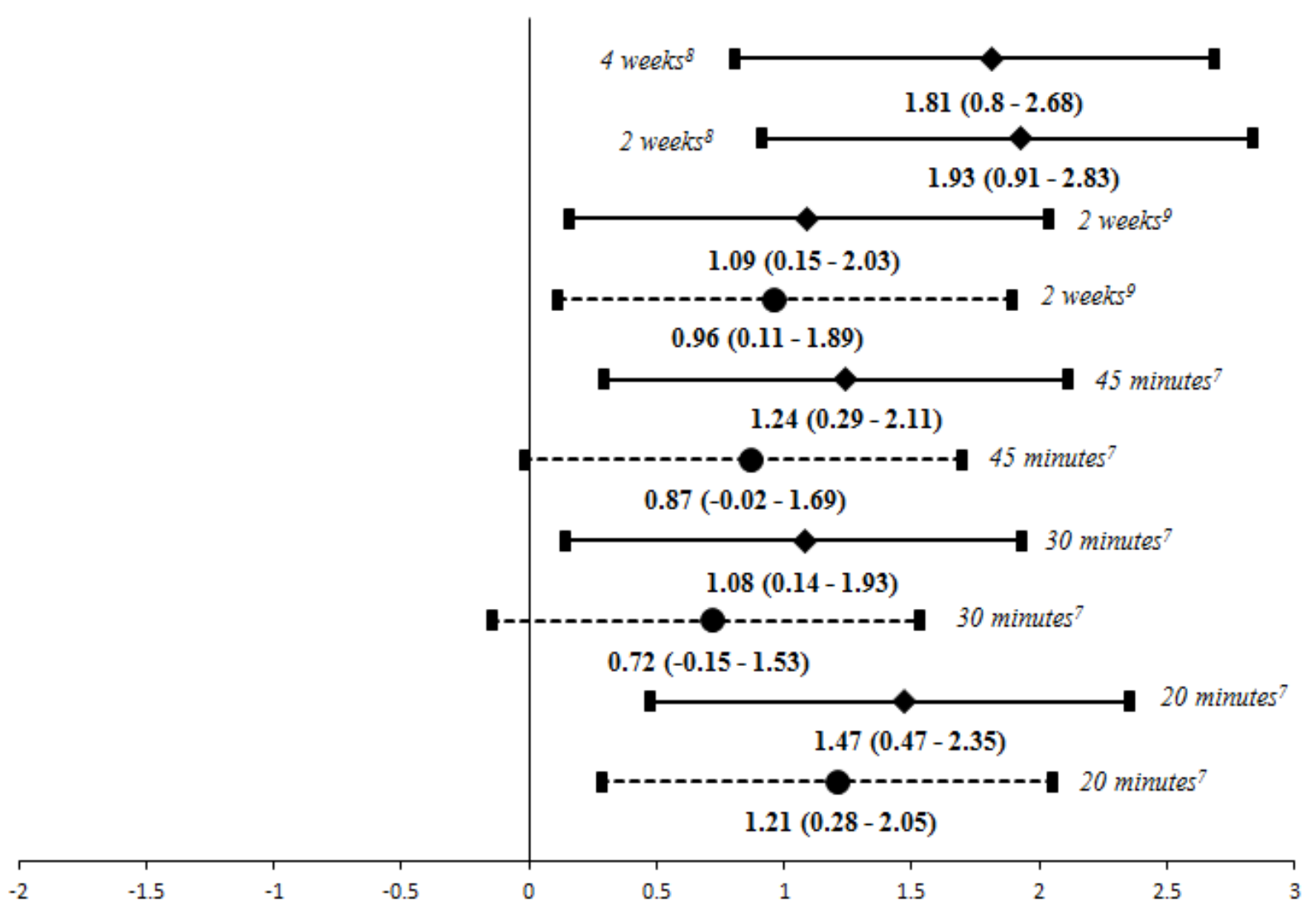

Non-Effective Treatment

Effective Treatment

Figure 1 - CAR effect sizes with 95\% confidence intervals: Diamonds with solid error bars (-) represent effect size point estimates for TENS interventions and 95\% confidence intervals, whereas circles with broken lines (-----) represent effect size point estimates for cryotherapy and $95 \%$ confidence intervals. All point measures and confidence intervals on the right of the vertical solid line represents beneficial and statistically significant effects (confidence intervals do not cross 0 ), whereas the left of the line represents non-beneficial and statistically insignificant effects. 
“Comparison of Transcutaneous Electrical Nerve Stimulation and Cryotherapy for Increasing Quadriceps Activation in Patients With Knee Pathologies" by Gabler CM, Lepley AS, Uhl TL, Mattacola CG

Journal of Sport Rehabilitation

(C) 2015 Human Kinetics, Inc.

Table 1 Summary of Study Designs of Articles Retrieved

\begin{tabular}{llll}
\hline Level of Evidence & Level of evidence & Number Located & Author (Year) \\
\hline 2 & $\begin{array}{l}\text { Randomized clinical } \\
\text { trial }\end{array}$ & 3 & Pietrosimone et al. (2009) \\
& & Pietrosimone et al. $(2011)^{8}$
\end{tabular}

Hart et al. (2012) $)^{9}$ 
Table 2 Characteristics of Included Studies

\begin{tabular}{|c|c|c|c|}
\hline & Pietrosimone et $\mathrm{al}^{7}$ & Pietrosimone et $\mathrm{al}^{8}$ & Hart et $\mathrm{al}^{9}$ \\
\hline Study Design & Randomized clinical trial & Randomized clinical trial & Randomized clinical trial \\
\hline Participants & $\begin{array}{l}33 \text { patients with tibiofemoral } \\
\text { osteoarthritis randomized to TENS } \\
\text { (TENS; } \mathrm{n}=10 ; \text { age } 56 \pm 10.1 \text { years), } \\
\text { focal joint cooling (CRYO; } \mathrm{n}=11 ; \text { age } \\
58 \pm 8.4 \text { years) or control (CON; } \mathrm{n}= \\
12 \text {; age } 54 \pm 9.9 \text { years) interventions. }\end{array}$ & $\begin{array}{l}36 \text { patients with tibiofemoral } \\
\text { osteoarthritis randomized to TENS and } \\
\text { exercise (TENS+EX; } n=12) \text {, placebo- } \\
\text { TENS and exercise ( } \mathrm{pTENS}+\mathrm{EX} ; \mathrm{n}=12) \text {, } \\
\text { or exercise only (EX; } \mathrm{n}=12) \\
\text { interventions. Subjects matched by }\end{array}$ & $\begin{array}{l}30 \text { patients with unilateral ACL deficiency } \\
(\text { age }=31.6 \pm 13 \text { years) randomized to } \\
\text { TENS and exercise (TENS+EX; } n=10) \text {, } \\
\text { cryotherapy and exercise (CRYO+EX; } n= \\
10), \text { or exercise only }(E X ; n=10) .\end{array}$ \\
\hline
\end{tabular}

Intervention Modality: TENS, TENS 210T; CRYO, 2 1.5-L bags of crushed ice; $\mathrm{CON}$, rest

\section{Length of intervention: N/A}

Dose: TENS $=45$ minute session; $\mathrm{CRYO}=20$ minute session; $\mathrm{CON}=20$ minute session

Outcome measure

\section{Main}

Findings
Quadriceps activation assessed via SIB technique and quantified with CAR.

Measurement time points: Baseline, 20 minutes, 30 minutes, and 45 minutes Primary findings: No differences in CAR between TENS and CRYO groups $(p>0.05)$. No differences in CAR between TENS and CRYO groups at any time point $(\mathrm{p} \geq 0.05)$. Compared to CON group, TENS group had higher percent change in CAR at 20,30, and quadriceps activation and TFOA grade.

Modality: TENS+EX and pTENS+EX, Select System TENS; EX, quadriceps strengthening

Length of intervention: 4 week

Dose: TENS+EX and pTENS+EX: 8 hours/day

Quadriceps activation assessed via SIB technique and quantified with CAR.

Measurement time points: Baseline, 2 weeks, and 4 weeks

Primary findings: No differences in CARs between groups at baseline ( $p>$ 0.05). TENS+EX group had higher CARs than EX group at 2 weeks $(p=0.02)$ and pTENS+EX group at 4 weeks $(p=0.03)$.
Modality: TENS+EX, TENS 210T; CRYO+EX, 2 1.5-L bags of crushed ice; EX, quadriceps strengthening

\section{Length of intervention: 2 week}

Dose: 4 sessions $(\mathrm{TENS}+\mathrm{EX}=$ duration of each session; $\mathrm{CRYO}+\mathrm{EX}=20$ minutes/session)

Quadriceps activation assessed via SIB technique and quantified with CAR.

Measurement time points: Baseline, day 1, and 2 weeks

Primary findings: CAR was different between groups at baseline $(\mathrm{p}<0.05)$. All subjects improved from baseline CARs at day 1 and 2 weeks ( $p<0.05$ ). No group differences in CARs at day 1 or 2 weeks $(p>0.05)$, accounting for differences at baseline. 


\begin{tabular}{|c|c|c|c|}
\hline & Pietrosimone et $\mathrm{al}^{7}$ & Pietrosimone et $\mathrm{al}^{8}$ & ${\text { Hart et } \mathrm{al}^{9}}^{9}$ \\
\hline & $\begin{array}{l}45 \text { minutes }(\mathrm{p}<0.05) \text {. CRYO group } \\
\text { had higher percent change in CAR than } \\
\text { the CON group only at } 20 \text { minutes }(\mathrm{p}< \\
0.05) \text {. }\end{array}$ & & \\
\hline & $\underline{\text { CAR Baseline (Mean } \pm \text { SD) }}$ & CAR Baseline (Mean $\pm 95 \% \mathrm{CI})$ & $\underline{\text { CAR Baseline (Mean } \pm \text { SD) }}$ \\
\hline & TENS $=0.79 \pm 0.13$ & TENS+EX = $0.78(0.71-0.86)$ & TENS+EX $=0.65 \pm 0.13$ \\
\hline & $\mathrm{CRYO}=0.87 \pm 0.10$ & pTENS+EX = $0.77(0.72-0.82)$ & $\mathrm{CRYO}+\mathrm{EX}=0.62 \pm 0.19$ \\
\hline & $\mathrm{CON}=0.81 \pm 0.13$ & $\mathrm{EX}=0.80(0.74-0.86)$ & $\mathrm{EX}=0.72 \pm 9.13$ \\
\hline & 20 minutes & 2 weeks & Day 1 \\
\hline & TENS $=0.84 \pm 0.13^{*}$ & $\mathrm{TENS}+\mathrm{EX}=0.94(0.91-0.96) \dagger$ & TENS+EX $=0.72 \pm 0.17$ \\
\hline & $\mathrm{CRYO}=0.91 \pm 0.8^{*}$ & pTENS+EX $=0.85(0.78-0.91)$ & $\mathrm{CRYO}+\mathrm{EX}=0.75 \pm 0.19$ \\
\hline & $\mathrm{CON}=0.78 \pm 0.13$ & $\mathrm{EX}=0.82(0.74-0.89)$ & $\mathrm{EX}=0.77 \pm 0.19$ \\
\hline & $\underline{30 \text { minutes }}$ & $\underline{4 \text { weeks }}$ & $\underline{2 \text { weeks }}$ \\
\hline & $\overline{T E N S}=0.86 \pm 0.9^{*}$ & 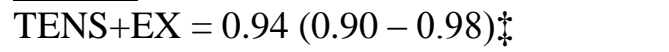 & $\overline{\mathrm{TENS}+\mathrm{EX}}=0.79 \pm 0.12$ \\
\hline & $\mathrm{CRYO}=0.91 \pm 0.7$ & pTENS+EX $=0.81(0.71-0.91)$ & $\mathrm{CRYO}+\mathrm{EX}=0.78 \pm 0.14$ \\
\hline & $\mathrm{CON}=0.79 \pm 0.14$ & $\mathrm{EX}=0.84(0.75-0.92)$ & $\mathrm{EX}=0.83 \pm 0.14$ \\
\hline & $\underline{45 \text { minutes }}$ & & \\
\hline & $\overline{\mathrm{TENS}}=0.91 \pm 0.10^{*}$ & & \\
\hline & $\mathrm{CRYO}=0.93 \pm 0.5$ & & \\
\hline & $\mathrm{CON}=0.81 \pm 0.14$ & & \\
\hline $\begin{array}{l}\text { Level of } \\
\text { Evidence }\end{array}$ & 2 & 2 & 2 \\
\hline $\begin{array}{l}\text { Validity } \\
\text { Score }\end{array}$ & PEDro 7/10 & PEDro 7/10 & PEDro $6 / 10$ \\
\hline Conclusion & $\begin{array}{l}\text { Both TENS and cryotherapy are } \\
\text { effective modalities for increasing } \\
\text { quadriceps activation in patients with } \\
\text { tibiofemoral osteoarthritis. }\end{array}$ & $\begin{array}{l}\text { Using TENS with exercise improves both } \\
\text { quadriceps activation and strength in } \\
\text { patients with tibiofemoral osteoarthritis } \\
\text { more effectively than exercise alone. }\end{array}$ & $\begin{array}{l}\text { Although all three interventions improved } \\
\text { quadriceps activation and strength in } \\
\text { patients with ACL deficiency, TENS with } \\
\text { exercise and cryotherapy with exercise }\end{array}$ \\
\hline
\end{tabular}




\begin{tabular}{|c|c|c|}
\hline Pietrosimone et $\mathrm{al}^{7}$ & Pietrosimone et $\mathrm{al}^{8}$ & Hart et $\mathrm{al}^{9}$ \\
\hline $\begin{array}{l}\text { Although cryotherapy did not sustain its } \\
\text { disinhibitory effect as long as TENS, } \\
\text { the TENS treatment duration was longer } \\
\text { than cryotherapy. Therefore, TENS } \\
\text { cannot be considered as superior to } \\
\text { cryotherapy for increasing quadriceps } \\
\text { activation. }\end{array}$ & $\begin{array}{l}\text { Increased quadriceps activation levels } \\
\text { observed after the removal of TENS } \\
\text { suggests a sustained treatment effect. } \\
\text { The capability of using TENS during } \\
\text { exercise makes it an attractive modality } \\
\text { for treating quadriceps activation failure } \\
\text { in patients. }\end{array}$ & $\begin{array}{l}\text { were no more effective than exercise } \\
\text { alone. } \\
\text { Subjects in the exercise only group had } \\
\text { higher CARs at baseline, therefore its } \\
\text { effectiveness at increasing quadriceps } \\
\text { activation was overestimated, and the } \\
\text { additive effect of TENS and cryotherapy } \\
\text { may have been masked. }\end{array}$ \\
\hline
\end{tabular}

Abbreviations: TENS, transcutaneous electrical nerve stimulation; CRYO, cryotherapy; CON, control; EX, quadriceps exercise; pTENS, placeboTENS; ACL, anterior cruciate ligament; N/A, not applicable; SIB, superimposed burst; CAR, central activation ratio; SD, standard deviation; 95\% CI, $95 \%$ confidence interval

*Significantly different than control group $(\mathrm{p}<0.05)$

$†$ Significantly different than exercise group $(\mathrm{p}<0.05)$

$\$$ Significantly different than placebo-TENS group $(\mathrm{p}<0.05)$ 
"Comparison of Transcutaneous Electrical Nerve Stimulation and Cryotherapy for Increasing Quadriceps Activation in Patients With Knee Pathologies" by Gabler CM, Lepley AS, Uhl TL, Mattacola CG

Journal of Sport Rehabilitation

(C) 2015 Human Kinetics, Inc.

Table 3 Treatment Effect Sizes and 95\% Confidence Intervals for Included Studies

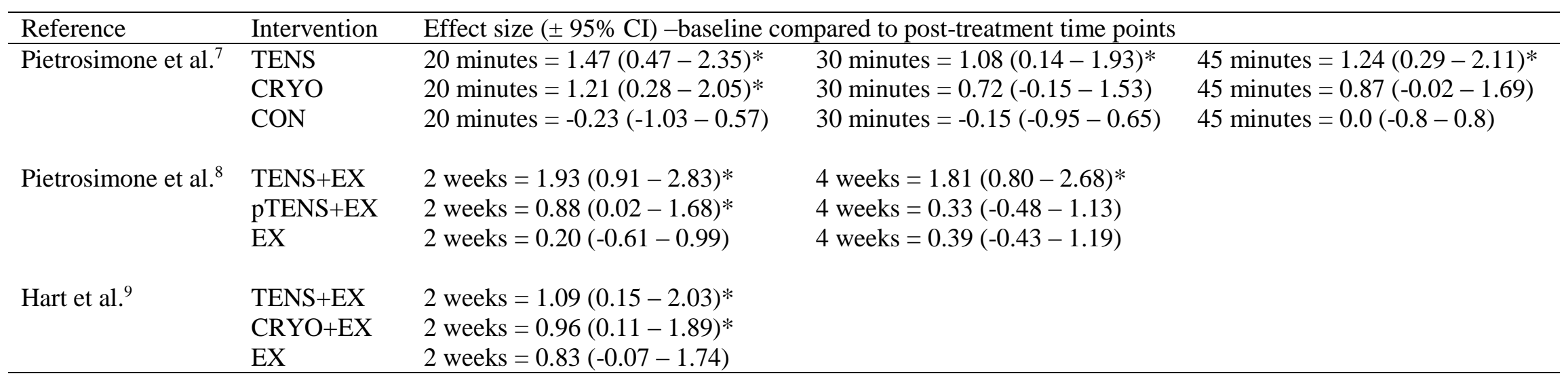

Abbreviations: TENS, transcutaneous electrical nerve stimulation; CRYO, knee joint cooling; CON, control group; PCB, placebo transcutaneous electrical nerve stimulation; EX, quadriceps exercise

*Statistically significant effect size (95\% confidence intervals do not cross 0$)$ 
"Comparison of Transcutaneous Electrical Nerve Stimulation and Cryotherapy for Increasing Quadriceps Activation in Patients With Knee Pathologies" by Gabler CM, Lepley AS, Uhl TL, Mattacola CG

Journal of Sport Rehabilitation

(C) 2015 Human Kinetics, Inc.

Table 4. Treatment Guidelines for Facilitating Quadriceps Activation

\begin{tabular}{llll}
\hline & Treatment Location & Treatment Parameters & Treatment Duration \\
\hline TENS & $\begin{array}{l}\text { Four } 2 \times 2 \text { inch self-adhesive } \\
\text { electrodes applied on the medial and } \\
\text { lateral superior and inferior borders of } \\
\text { the patella. }\end{array}$ & $\begin{array}{l}\text { Pulse frequency }=150 \mathrm{~Hz} \\
\text { Pulse Duration }=150 \mu \mathrm{s}\end{array}$ & $\begin{array}{l}\text { Throughout the duration of exercise } \\
\text { and as often as needed outside of } \\
\text { exercise. }\end{array}$ \\
& $\begin{array}{l}\text { Two currents (pairs of electrodes) } \\
\text { should be crossed to encompass the } \\
\text { most surface area. }\end{array}$ & $\begin{array}{l}\text { Stimulation Intensity }=0-80 \mathrm{~mA} \text { (no } \\
\text { presence of muscle contraction) }\end{array}$ \\
Cryotherapy & $\begin{array}{l}\text { Secured to the anterior and posterior } \\
\text { aspects of the knee with a } \\
\text { compression wrap }\end{array}$ & Two, 1.5 L bags of crushed ice & $\begin{array}{l}\text { 25 minutes (duration can be increased } \\
\text { in patients with higher contents of } \\
\text { subcutaneous adipose tissue). }\end{array}$ \\
\hline
\end{tabular}

TENS, transcutaneous electrical nerve stimulation; Hz, Hertz; $\mu \mathrm{s}$, microseconds; mA, milliamps; L, liter 